\title{
Homossexualidade, Bissexualidade e HIV/AIDS no Brasil Uma Bibliografia Anotada das Ciências Sociais e Afins*
}

\author{
CARMEN DORA GUIMARÃES \\ VERIANO TERTO JR. \\ RICHARD G. PARKER
}

\section{Apresentação}

Esta bibliografia anotada sobre homossexualidade, bissexualidade e AIDS no Brasil iniciou-se de forma modesta, como parte do relatório final de uma investigação intitulada "Práticas sexuais e conscientização sobre AIDS; uma

* A elaboração deste documento contou com o apoio da Unidade de Pesquisa Social e Comportamental do Programa Global de AIDS da Organização Mundial de Saúde e do Instituto de Medicina Social (IMS) da Universidade do Estado do Rio de Janeiro (UERJ). Agradecemos a Regina Tinoco, bibliotecária do Instituto de Medicina Social, a Jane Fortes, responsável pelo Centro Referencial do Sistema de Bibliotecas da UERJ, e a Maria Izabel Moreira Pinto, bibliotecária do Programa de Pós-Graduação em Antropologia Social da Universidade Federal do Rio de Janeiro, pela ajuda que nos prestaram na pesquisa bibliográfica e na orientação dos procedimentos visando sua apresentação. Agradecemos ao nosso colega, Pedro de Souza, do Grupo Pela VIDDA — São Paulo, pela ajuda na revisão do texto. À Regina Marchese, secretária do IMS, nosso reconhecimento especial pelo trabalho datilográfico. Além disso, Richard G. Parker agradece a Fundação de Apoio à Pesquisa do Estado do Rio de Janeiro (FAPERJ), pelo seu apoio a pesquisas sobre a dimensão social da AIDS nn Rrasil 
pesquisa sobre o comportamento homossexual e bissexual", realizada através do Instituto de Medicina Social/UERJ. Na medida que avançávamos no levantamento de títulos, achamos importante facilitar o acesso de outros ao pensamento já produzido, tanto para permitir uma melhor orientação ao estudioso do assunto, quanto para estimular novos investigadores a se dedicarem a este tema.

O tratamento sociológico dado à AIDS não representa uma intromissão em seara alheia; provém do fato de que o vírus da imunodeficiência adquirida, o HIV, se transmite por meio de relações entre pessoas, nos obrigando a desfazer as tradicionais fronteiras disciplinares que separam o indivíduo, a saúde e a doença, de sua vivência social e sexual. Hoje, a força e o alcance da epidemia, ainda sem cura ou tratamento à vista, é necessariamente interdisciplinar, envolvendo clínicos, epidemiólogos, psicólogos, sociólogos e antropólogos, entre outros, no seu estudo. Podemos mesmo dizer que, depois da AIDS, nada será como antes, sobretudo aquelas bem guardadas práticas do cotidiano, onde o homossexualismo e o bissexualismo mascu-lino detêm lugar de destaque. As anotações bibliográficas dos anos 60 até o presente permitem perceber o quanto a construção social dessas sexualidades foi bruscamente alterada por causa da AIDS, e quão trágica têm sido as consequências do preconceito e da discriminação para a vida e a sobrevida de pessoas HIV positivas ou vivendo com a síndrome neste país.

Esperamos que esta primeira compilação, reunindo mais de cem trabalhos - pesquisas, teses, artigos, relatórios, projetos e livros - coletados em instituições e fontes particulares no Rio dc Janeiro e em São Paulo, leve à descoberta de novos títulos e incentive a formulação de propostas inovadoras para o futuro. Talvez mais importante será saber que nosso esforço resultou no maior envolvimento de pessoas para uma criteriosa reflexão e uma ação mais realista diante da epidemia no Brasil. Queiramos ou não, ela concerne a todos nós.

ALMEIDA, Horácio. Dicionário de termos eróticos e afins. Rio de Janeiro: Civilização Brasileira, 1981.

Registro de termos referentes a experiências, atos, comportamentos e atitudes sexuais, com seus respectivos significados ou versões, inclusive aqueles relativos ao homossexualismo masculino e à sua representação no imaginário popular.

ALMEIDA, Sergio Alves de. Michê. Rio de Janeiro, PUC, Faculdade de Psicologia. 1984. Dissertação de Mestrado em Psicologia Social. 
A prostituição viril na cidade de São Pauloé estudada a partir de um bordel masculino da periferia e de depoimentos dos próprios prostitutos.

ALTMAN, Dennis."Down Rio Way". Christopher Street, v. 4, n. 8, p. 22-27, Apr. 1980. New York.

Através de suas impressões e vivências como visitante, o autor traça um retrato da vida do homossexual masculino no Rio de Janeiro e em São Paulo no final dos anos 70. Sua percepção aguda revela facetas singulares desse universo, tais como a "transa" nas praias e os jogos de sedução, além de outros aspectos sociais e políticos.

ARAÚJO, Rejane e VALLINOTO, Cristina. “AIDS e liberalização: o início de um longo debate". Comunicações do Iser, Rio de janeiro, v. 4, n. 17, p. 28-31, dez. 1985.

Discute o fato de se atribuir às práticas homossexuais masculinas uma promiscuidade que potencializa os efeitos perversos da AIDS. Propõe uma reflexão sobre a trajetória da sexualidade e da homossexualidade nos últimos tempos, para uma melhor compreensão dos preconceitos associados à epidemia.

ASSUNÇÃO, Aroldo e MOTT, Luiz. "Gilete na carne: etnografia das automutilações dos travestis da Bahia". Temas Imesc, v. 4, n. 1, p. 41-56, 1987.

Etnografia realizada junto aos travestis baianos para verificar de que maneira eles convivem com a violência policial, o machismo e a hipocrisia característicos daquela sociedade. Descreve alguns comportamentos adotados pelos travestis para conviver com seu próprio corpo e sua sexualidade.

AUGRAS, Monique et al. "O espaço do homossexualismo na psicologia contemporânea". Arquivos Brasileiros de Psicologia, Rio de Janeiro, v. 34, n. 3, p. 25-40, jul./set. 1982.

Mesa-redonda que reuniu psicólogos clínicos para o exame do "problema do homossexualismo", segundo a optica atual da psicologia. Em geral, os participantes opinaram sobre o homossexualismo com um discurso teórico e ideológico, sem demonstrar um conhecimento objetivo do assunto. Houve dificuldade em estabelecer definições ou posturas claras, o que poderia conduzir a um novo espaço de produção de conhecimento. A autora conclui que a psicologia possui o discurso do saber, mas ainda se mantém muito distante da realidade. 
BARROS, J. F. P., SANTOS, M. L., e TEIXEIRA, M. L. O rodar das rodas: dos orixás e dos homens. Rio de Janeiro: Funarte, 1985 (Concurso Sílvio Romero).

Os autores buscam compreender a inserção da homossexualidade masculina nos sistemas simbólicos do candomblé e na conformação da mitologia desta religião.

BASTOS, José Cândido. "Homossexualidade masculina”. Jornal Brasileiro de Psiquiatria, v. 28, n. 1-4, p. 7-11, 1979.

Mostra a evolução dos conceitos referentes à etiologia da homossexualidade masculina, em seus aspectos genéticos, endócrinos, sociológicos e psicológicos. Com base nesse estudo e no exame de material clínico colhido junto a quatro casos de homossexualidade masculina (dois ativos e dois passivos), o autor ressalta a importância que as fantasias agressivas têm na gênese da homossexualidade, particularmente nos homossexuais passivos. Conclui que a intensidade dos conflitos agressivos poderá ser um impedimento para relações heterossexuais.

BIAO, Armindo Jorge. "Théâtralité et spectacularité: les pratiques homosexuelles masculines dans le Candomblé". Sociétés, n. 17, p. 23-25, mars 1988.

As práticas homossexuais nos cultos afro-brasileiros, em particular no candomblé, são analisadas através da teatralidade de alguns comportamentos observados e de sua apreensão pelo imaginário popular brasileiro, tanto no Rio de Janeiro quanto no Nordeste do país.

BIRMAN, Patrícia. "Identidade social e homossexualismo no candomblé". Religião e Sociedade, Rio de Janeiro, v. 12, n. 1, p. 2-21, 1985.

$\mathrm{O}$ estudo sobre $\mathrm{o}$ homossexualismo e a construção das identidades masculina e feminina em um terreiro "misto", de candomblé e umbanda, permitiu verificar como este caso específico se articula com o universo mais amplo da sexualidade e da religião. A análise incide sobre as representações de um pai-de-santo gay desse terreiro e de seu desempenho durante uma festa anual cujo tema é sexualidade. No rito de possessão da Pomba-Gira, espírito feminino incorporado pelo pai-de-santo, a personagem reveste-se de alto luxo e requinte, em contraste com a figura debochada e vulgar que comumente a representa quando é incorporada por mães-de-santo. Sendo os papéis rituais prefixados, esta incorporação é inteligível para n púhlico presente; ganha em eficácia 
simbólica na medida em que reforça as representações do masculino e feminino em sua vida cotidiana.

CARRARA, Sérgio e MORAES, Cláudia. "Um vírus só não faz doença". Comunicações do Iser, Rio de Janeiro, ano 4, n. 17, p. 5-19, dez. 1985.

Discute um campo determinado de relações políticas e sociais que se arma em torno da AIDS, em especial os modelos médicos de explicação e de tratamento. Analisa aspectos do imaginário social, fonte da criação de novas metáforas e da reincorporação de outras, que transformam a síndrome em metadoença - várias em uma só. A homossexualidade parece ser feita de encomenda para enfeixar todos esses processos, constituindo-se em "viga-mestra" por onde passa a maioria das associações simbólicas da AIDS.

CARRARA, Sérgio e MORAES, Cláudia. "Um mal de folhetim". Comunicações do Iser, Rio de janeiro, ano 4, n. 17, p. 20-27, dez. 1985.

Crítica ao tratamento sensacionalista dado pela imprensa à questão da AIDS no Brasil. Alguns aspectos da face pública da doença são mais profundamente analisados, inclusive uma ampla discussão sobre a homossexualidade. Os modelos médicos e outras idéias de realidades mais "avançadas" são examinados, bem como o papel da informação correta na prevenção da epidemia.

CHRYSOSTOMO, Antônio. Caso Chrysostomo: o julgamento de um preconceito. Rio de Janeiro: Codecri, 1983.

Relato autobiográfico, em tom jornalístico, sobre os preconceitos que persistem contra o homossexualismo masculino no início dos anos 80 , com particular ênfase na sua manipulação pelo aparato judiciário-psiquiátrico-policial e pela opinião pública.

COSTA, Jurandir Freire. Ordem médica e norma familiar. Rio de Janeiro: Graal, 3ª ed., 1983. (1. ed. 1979)

Discussão sobre o estado higiênico que se instaurou no Brasil a partir do século XIX, quando a medicina condenava os celibatários, libertinos e homossexuais à categoria de irresponsáveis e adversários do bem-estar biologico-social. A nova ordem deu um passo adiante em relação aos métodos da Inquisição, sobrepondo um controle normativo-terapêutico ao antigo controle moral-religioso. Ao imperar o padrão da normalidade, abriu-se uma brecha para a entrada disciplinar da psiquiatria, reforçando o controle científico sobre os comportamentos desviantes em relação ao modelo monogâmico e conjugal. 
CUNHA, Manuela Carneiro da. Sobre definições "sexuais" e classificações: a retórica do universo homossexual. Campinas: [1.n.], 1974.

Estudo que busca compreender os critérios de definição e classificação sexuais, a partir da homossexualidade e dos saberes médico-psicossociais a seu respeito.

DANIEL, Herbert. "A síndrome do preconceito". Comunicações do Iser, Rio de Janeiro: v. 4, n. 17, p. 48-56, dez. 1985.

Originalmente publicado em 1983, como anexo no livro Jacarés e lobishomens, escrito em co-autoria com Leila Miccolis, quando a AIDS era recém chegada ao Brasil como "câncer gay". Discute os preconceitos veiculados pela imprensa e pelo campo médico com respeito a AIDS e homossexualidade, agravando a discriminação preexistente e aumentando o pânico na população.

DANIEL, Herbert. “A síndrome dos nossos dias". Desvios. São Paulo, p. 108-114, 1986.

Aborda aspectos culturais relacionados com a AIDS, em particular as ditas verdades médicas e religiosas sobre o tema; além disso, analisa os significados que a epidemia e os seus efeitos vêm adquirindo na sociedade. São desmistificados os preconceitos e tabus que relacionam a AIDS com a homossexualidade masculina.

DANIEL, Herbert. "A AIDS é um tigre de papel... higiênico". Radis Tema, FIOCRUZ, Rio de Janeiro, n. esp., p. 53-62, out. 1987.

De maneira detalhada e pertinente, são questionadas as representações que a AIDS desperta no imaginário social e no discurso médico. O aparato ideológico formado em torno dessa epidemia é dissecado para mostrar como ele impede que a AIDS seja vista como uma doença entre outras. Dentre as mistificações diversas, dois termos ressaltam os tabus da cultura capitalista: sexo e morte. A medicalização dos corpos e da sexualidade ganha destaque e é analisada de forma crítica, assim como a imposição da noção de identidade ao desejo homossexual e os efeitos políticos da "liberação gay" dos anos 70. A AIDS surge como mais um canal para expressar mistificações, juízos de valor e julgamentos moralistas, que atuam de forma decisiva na experiência homossexual.

DANIEL, Herbert. Vida antes da morte. Rio de Janeiro: Jaboti, 1989.

Pequena coletânea de artigos autobiográficos, que relatam a vivência e as impressões pessoais do autor ao se descohrir doente de AIDS. Os preconceitos 
que relacionam AIDS e homossexualidade são fortemente criticados, além de outras mistificações que a epidemia suscita no imaginário da sociedade ocidental dos anos 80 .

DANIEL, Herbert, e MICCOLIS, Leila. Jacarés e lobishomens (dois ensaios sobre a homossexualidade). Rio de Janeiro: Achiamé, 1983.

Com humor e poesia, este livro apresenta-se como um trabalho não acadêmico sobre o tema das homossexualidades, do ponto de vista da vivência homossexual dos dois autores. De autoria de H. Daniel, o primeiro ensaio, "Os anjos do sexo", examina os significados, as identidades e os papéis que a homossexualidade vem adquirindo no Brasil. O segundo ensaio, de L. Miccolis, "Prazer, gênero de primeira necessidade", relata e analisa a história interna do movimento homossexual brasileiro, sendo a autora uma das principais militantes. No texto final, "Anexo: A síndrome do preconceito", $\mathrm{H}$. Daniel abre uma primeira discussão sobre a face social da AIDS no Brasil, na época em que se instaurou uma forte associação entre a epidemia e a homossexualidade masculina.

DANIEL, Herbert e PARKER, Richard. AIDS: A terceira epidemia (ensaios e tentativas). São Paulo: Iglu, 1991.

Uma coletânea de artigos tratando de AIDS, sexualidade e política no contexto brasileiro. Há um enfoque especial sobre a construção social da homossexualidade e a cultura sexual no Brasil. Diversos artigos examinam a importância desses assuntos para entender a transmissão do HIV na população brasileira e para fundamentar programas de prevenção e educação.

DANIEL, Herbert e PARKER, Richard G. "A Terceira Epidemia: o exercício da solidariedade". In: H. Daniel e R. Parker, AIDS, a terceira epidemia (ensaios e tentativas). São Paulo: Iglu, p. 13-30, 1991.

Identificada como a "peste gay" no início dos anos 80 no Brasil, o impacto social da AIDS serve como importante revelador das condições de pobreza e carência em que vive a maioria da população. Com o advento da epidemia, a crise do sistema de saúde tornou-se mais evidente e, somado ao pânico gerado pela desinformação, acirrou os preconceitos e a discriminação contra o homossexualismo. No final da década o homossexual permanece como "bode expiatório" da AIDS, dificultando uma compreensão melhor dos mecanismos de transmissão do vírus e a adoção de medidas preventivas eficazes. Em resposta a este estado de coisas, pessoas e grupos da sociedade civil têm se organizado para produzir e disseminar informações corretas sobre a AIDS, prestar assis- 
tência àqueles mais necessitados e lutar pelos direitos de cidadania de pessoas HIV positivas ou convivendo com AIDS. A idéia que norteia estes esforços se expressa no termo solidariedade, tida como a melhor arma contra o preconceito e, neste momento, a mais eficaz vacina contra o vírus.

DANIEL, Herbert e PARKER, Richard. "Brazil: the goal of solidarity" [Brasil: a meta da solidariedade]. In: The Third Epidemic: repercussions of the fear of AIDS. London: The Panos Institute, p. 154-160, 1990.

Versão reduzido do artigo "A terceira epidemia", citado acima.

DURST, R. Madame Satã. São Paulo: Brasiliense, 1985.

Biografia de conhecida personagem carioca, revelando aspectos históricos e etnográficos sobre os hábitos, costumes e o homossexualismo masculino no Rio de Janeiro, na primeira metade deste século.

ERDMAN, Regina Maria. Reis e rainhas do desterro: um estudo de caso. Florianópolis, Universidade Federal de Santa Catarina, 1981. Dissertação de Mestrado em Antropologia.

Etnografia sobre o meio homossexual masculino de Florianópolis, visando a verificar como as diversas categorias de homossexuais vêem a si mesmos, bem como interagem social e sexualmente. $\mathrm{O}$ trabalho foi desenvolvido junto a dois grupos específicos: os homossexuais adultos e seus jovens parceiros sexuais, e os travestis prostitutos. É salientada a especificidade sociocultural das categorias prostituição e homossexual em Florianópolis, comparando-as com categorias similares geradas do contexto americano e com tipologias da realidade norte/nordestina do Brasil, segundo Peter Fry.

FAERCHTEIN, Lucila. "Homossexualidade masculina". Jornal Bras. de Psiquiatria, v. 31, n. 3, p. 151-165, 1982.

A homossexualidade masculina é abordada como questão clínica, através da revisão detalhada de aspectos tais como a sua definição, etiologia e tratamento. Questiona-se, na óptica adotada, a sua inclusão na categoria de doença mental. São também examinados trabalhos de outras ciências - antropologia, história e zoologia comparada - para obter uma compreensão mais ampla desse assunto, visto pela autora como muito polêmico.

FARIAS, Francisco Ramos de. "Reflexões sobre a homossexualidade masculina". Arquivos Brasileiros de Psicologia, Rio de Janeiro, v. 38, n.3, p. 101-108, jul./set. 1986. 
Situa e discute, no escopo da teoria psicanalítica, três hipóteses sobre a homossexualidade masculina. Procura analisar, através de um modelo explicativo, casos clínicos de pacientes abertamente homossexuais, ou que evidenciam este componente no curso do tratamento, sob quatro ângulos distintos: a identificação; a estrutura da rede de interações familiares; a repetição de um padrão comportamental; e relacionada ao corpo e ao investimento libidinal.

FIGUEIROA, Lucia. "O diagnóstico de homossexualidade: modificações ocorridas no novo código". Jornal Bras. de Psiquiatria, v. 31, n. 1, p. 19-23, 1982.

Até 1973, a homossexualidade foi classificada na categoria de doença mental, segundo o Código Internacional de Doenças (CID). Opina a autora que, com a liberalização sexual, as minorias passaram a ter maior poder político, a ponto de influírem sobre a exclusão da homossexualidade dessa categoria. Isto se reflete no CID que, em grande parte, baseia-se no Manual Estatístico de Doenças (DSM) americano. As diversas classificações da homossexualidade ao longo do tempo são apresentadas, desde da primeira edição do DSM até o atual DSM III, em que a classificação é de "homossexualidade egodistônica". Essa categoria é tida como uma variante do comportamento sexual normal, sem as características de uma patologia mental. São analisados os conceitos de doença mental, assim como alguns aspectos clínicos, sociais e políticos da homossexualidade.

FONSECA, Guido. "A prostituição masculina em São Paulo". Arquivos de Polícia, São Paulo, v. 30, 2. sem., 1977.

A prostituição masculina na cidade de São Paulo é vista numa abordagem legal e policial. Paralelamente, são fornecidos dados etnográficos sobre os circuitos e as diversas modalidades desta prática.

FOSTER, Stephen W. "Homosexuality and the Inquisition in Brazil: 15911592". Gay Sunshine, San Francisco: issue 38/39, [s. p.] winter 1979.

Análise do tratamento dado pela Santa Inquisição à sodomia na época do Brasil colonial, em particular os casos levados a julgamento e resultantes em condenação.

FRY, Peter. "Léonie, Pombinha, Amaro e Aleixo: prostituição, homossexualidade e raça em dois romances naturalistas". In: Alexandre Eulálio et al. Caminhos cruzados: linguagem, antropologia e ciências naturais. São Paulo: Brasiliense, 1982, p. 33-51. 
Examina a produção de identidades sexuais no Brasil no final do século XIX através do estudo etnográfico de dois romances: $O$ cortiço (1890), de Aluísio Azevedo, e Bom-Crioulo (1895), de Adolfo Caminha. Embora na época as teorias biomédicas de higienização e o romance naturalista fossem dominantes, esses escritores desenvolvem uma lógica própria, quase antropológica, ao descreverem suas respectivas realidades. Aoclassificarem os principais tipos sociais de seus romances - a prostituta, o homossexual e o negro - segundo o conjunto das relações sociais e as representações coletivas sobre a marginalidade em cada contexto, rompem com o discurso médico individualizante então em voga.

FRY, Peter. "Da hierarquia à igualdade; a construção histórica da homossexualidade no Brasil". In: Fry, Peter. Para inglês ver: identidade $e$ política na cultura brasileira. Rio de Janeiro: Zahar, p. 87-115, 1982.

Ensaio precursor que investiga a construção social da identidade sexual masculina em quatro contextos sociais distintos, nomeados de sistemas classificatórios "A", "B", "C" e "D". No sistema "A", calcado na periferia de Belém, as categorias homem e bicha simbolizam a nítida segregação de papéis de gênero e uma rígida hierarquia entre o parceiro "ativo" e o "passivo". No sistema "B", dos grandes centros urbanos, as categorias homens e entendido e seus respectivos atributos de atividade e passividade independem do papel de gênero. Há uma certa permissividade nas relações sexuais entre indivíduos que se dizem semelhantes, das classes médias e altas, porquanto o sistema "A" se mantém nas classes baixas. O sistema "C" refere-se ao modelo médico-jurídico importado da Europa nos fins do século XIX e à sua influência sobre a teoria biomédica sobre o homossexualismo no Brasil. Finalmente, a partir de 1960, o sistema " $D$ " parece romper com os sistemas dualistas estabelecidos e introduz uma classificação tripartida: homossexual, bissexual e heterossexual. A "nova" identidade homossexual baseia-se na idéia de orientação sexual e de relações igualitárias, em rejeição aos modelos anteriores; ainda assim, o sistema "A" mantém-se hegemônico nas classes mais baixas e no interior do país, onde co-existe ou compete com os demais. Todos os quatro modelos, esclarece o autor, mantêm a oposição homossexual/heterossexual como dois grupos distintos, indicando que lógica dualista subjacente permanece inalterada. A análise comparativa permite demonstrar, ao final, que a naturalidade atribuída ao sexo e às categorias sexuais são construções sócio-históricas, colocando em cheque as ditas verdades imutáveis das ciências médicas. 
FRY, Peter. "Febrônio Indio do Brasil: onde cruzam a psiquiatria, a profecia, a homossexualidade e a lei". In: Alexandre Eulálio et al., Caminhos cruzados: linguagem, antropologia e ciências naturais. São Paulo: Brasiliense,p. 65-80, 1982.

Discute aspectos sociais e políticos da rotulação com estigma para desvendar os processos de construção ideológica de "tipos" anti-sociais e de sua consolidação em modelos normativos "naturais". Toma o caso jurídico de Febrônio Indio do Brasil como representativo desse processo na sua forma mais dramática. Além de evidenciar as idéias médico-legais em ação nos anos 20 e 30 , a sua acusação de "loucura moral" - reunindo de uma só vez a homossexualidade, o crime e a endocrinologia - cumpriu importante papel didático junto à população, dada a ampla repercussão nacional do caso. Hoje ocorre $o$ processo inverso: o mesmo personagem serve de peça fundamental de combate àquelas idéias estigmatizantes.

FRY, Peter. "Homossexualidade masculina e cultos afro-brasileiros". In: FRY, Peter. Para Inglês ver: identidade e política na cultura brasileira.

A partir de um estudo antropológico realizado em Belém (cerca de 1974) sobre o significado da relação entre a homossexualidade masculina e os cultos afro-brasileiros naquele local, propõe-se como hipótese exploratória que os papéis de gênero são diferencialmente construídos segundo a classe social e o contexto regional. Definições de gênero masculino e feminino no Norte/Nordeste do Brasil se mostram mais rígidos do que no Sul/Sudeste, indicando que as diferenças econômicas e socioculturais entre as regiões Norte e Sul são relevantes para compreender como a construção local da sexualidade se relaciona com a estrutura social.

FRY, Peter. "Male homosexuality and spirit possession in Brazil". Journal of Homosexuality, v. 11, n. 3/4, p. 137-153, 1985.

Versão inglesa do artigo "Homossexualidade masculina e cultos afro-brasileiros", citado acima.

FRY, Peter e MACRAE, Edward. O que é homossexualidade? São Paulo: Brasiliense, 1983. Coleção Primeiros Passos.

A dimensão política e social da homossexualidade é discutida neste pequeno livro de linguagem instigante, acessível a um público leigo. Ainda que os capítulos não obedeçam a uma rígida seqüência linear, organizam-se em torno de três eixos centrais: uma perspectiva histórica da homossexualidade com ênfase no masculino, uma análise comparativa e uma breve discussão da 
homossexualidade feminina. De início a filiação antropológica da abordagem recoloca a questão no seu devido lugar histórico e social. Os capítulos seguintes tratam da história da luta homossexual e da problemática do movimento gay no Brasil, tendo em vista as suas relações com a estrutura autoritária e conservadora de nossa formação social. Ao revelar dimensões ocultas do pensamento brasileiro sobre a questão da homossexualidade desde os tempos coloniais, os autores desnudam as explicações teóricas para revelar sua dimensão ideológica. Indicam que para compreender os desejos homossexuais, deve-se também compreender os desejos heterossexuais, pois ambos compartilham a mesma sociedade e cultura.

GALVÃO, Jane. "AIDS: a 'doença' e os 'doentes ". Comunicações do Iser, Rio de Janeiro, ano 4, n. 17, p. 42-47, dez. 1985.

Baseada em levantamento, realizado pela autora, de material jornalístico sobre a AIDS na primeira metade da década de 1980. Os preconceitos e as mistificações associadas à epidemia e ao doente são analisados, principalmente aqueles que desqualificam comportamentos homossexuais e bissexuais como "promíscuos", "patológicos" ou "desviantes".

GAUDERER, Christian E. "Homossexualidade masculina e lesbianismo". Medicina de Hoje, v. 6, n. 63, p. 236-242, jun. 1980.

Discute a evolução da conceituação social e psiquiátrica da homossexualidade, até o posicionamento da Associação Americana de Psiquiatria em 1980 ("homossexualidade, por si só, não é uma desordem psiquiátrica"). São abordadas a incidência, as motivações e as causas psicodinâmicas e sociais do homossexualismo, bem como a estrutura psíquica e comportamental dos homossexuais. 'nfase é dada às causas e conseqüências dessa "variação de comportamento social", e não à idéia do homossexual como um doente.

GAUDERER, Christian E. "Homossexualidade e adolescência". Jornal de Pediatria, v. 56, fasc. 5, p. 335-336, maio 1984.

A partir de definições relativas a sexualidade e homossexualidade, $o$ autor enumera quatro afirmativas gerais sobre o comportamento homossexual do adolescente. \# luz desta conceituação, aponta para alguns problemas médicos e sociais que devem ser do conhecimento do pediatra, para que possa esclarecer $o$ adolescente, os seus pais e as organizações comunitárias em que eles interagem. 
GUIMARÃES, Carmen Dora. O homossexual visto por entendidos. Rio de Janeiro, UFRJ, Museu Nacional, 1977. Dissertação de Mestrado em Antropologia Social. Apresenta encarte fotográfico.

Pesquisa antropológica sobre a construção da identidade homossexual masculina a partir de uma rede (network) de amigos, autodefinidos como homossexuais, das camadas médias ascendentes da Zona Sul do Rio de Janeiro. A análise do estilo de vida e do ethos dessas pessoas revela que seus critérios de status e prestígio interagem com as ideologias de hedonismo e da política do corpo de setores "avançados" do contexto sociocultural, levando-os a construir uma identidade homossexual tida como absolutamente normal. Os "anormais" e "doentes" são os outros, de maneirismos efeminados, sem cultura e integrantes das classes sociais mais baixas, consoante à lógica de classificação da estrutura social brasileira.

GUIMARÃES, Carmen Dora. "O homossexual face a norma familiar: desvios e convergências”. In: Reprodución de la populación y desarrollo. Consejo Latinoamericano de Ciencias Sociales, São Paulo, v. 4, p. 359-375, 1980.

Discute a maneira pela qual a identidade homossexual, desviante e estigmatizada, supostamente à margem da ordem familiar, se insere nesta ordem. Os dados foram extraídos de uma pesquisa antropológica da autora junto ao Somos-Rio de Janeiro, grupo de militância homossexual do início dos anos 80 . Naquele meio, a família era vista como repressora e manipuladora de afetos, ao contrário do grupo Somos, tido como liberal, igualitário e de plena aceitação. Esta representação, analisada à luz de sua inserção no contexto social e histórico, reflete a ideologia da política sexual de determinados setores "avançados" do meio urbano e a idéia de "abertura" que marcou esse período. Esse conjunto de fatores permitiu a esses homossexuais maior legitimidade e aceitação, inclusive a possibilidade de rever a sua posição na família.

GUIMARÃES, Carmen Dora. Um discurso de retorno: a reconstrução da identidade homossexual. Comunicação apresentada na XIII Reunião da Associação Brasileira de Antropologia, 4-7 abr. 1982, São Paulo.

Discute a especificidade da militância homossexual, a partir de uma situação de crise no grupo Somos-Rio de Janeiro, gerada no seu período inicial. A disputa pela liderança do grupo e a definição de sua identidade pública se revelou na disputa em torno do conceito do termo homossexual, ainda que o "racha" do Somos tenha sido atribuído à presença de uma participante heterossexual naquele meio (a própria pesquisadora). A retirada intempestiva da minoria dissidente levou à criação do grupo Auê e à reestruturação do Somos. 
Essa situação de confronto, além de delinear com maior clareza os mecanismos internos de inclusão e exclusão de membros, permitiu vislumbrar o lugar que a luta homossexual viria ocupar face às demais lutas organizadas — da mulher e do negro - que, à época, também reivindicavam voz e vez.

GUIMARÃES, Carmen Dora. "Casos e acasos". Anais. São Paulo: ABEP, v. 1, 1984, p. 575-586. IV Encontro da Associação Brasileira de Estudos Populacionais, Aguas de São Pedro.

Estudo de três formas de relacionamento homossexual masculino, a partir de uma rede restrita de amigos, de 35 a 40 anos, residentes na Zona Sul do Rio de Janeiro. São descritos e analisados: a situação de pegação, surgida ao acaso, em que o vínculo é exclusivamente sexual; a situação de caso, em que o envolvimento entre os parceiros é sexual e amoroso; e a relação de amizade. entre pares homossexuais, onde é privilegiado o afeto sem sexo.

GUIMARÃES, Carmen Dora. "AIDS e a mulher". Jornal do Brasil. Idéias/Ensaios, 28 out. 1990. p. 6-7. Comunicação apresentada no Encontro "Impacto Social da AIDS no Brasil”, UERJ/Instituto de Medicina Social, Fundação Ford, 16 -18 ago. 1990.

No Brasil, a homossexualidade e a bissexualidade masculina lideram as estatísticas oficiais de AIDS como as principais categorias de transmissão do vírus HIV. Nos últimos três anos, houve um aumento significativo de casos de AIDS em mulheres e crianças, sugerindo uma importante mudança no perfil epidemiológico. Nesse artigo, essa suposta novidade é questionada através da apresentação e outros fatores relativos a notificação e subnotificação da AIDS, em especial com relação à mulher. É proposta como hipótese que a mulher estaria mais presente no rol da epidemia há pelo menos seis anos, não estivesse a AIDS enquadrada no modelo masculino da sexualidade.

GUIMARÃES, C. D., DANIEL, H., GALVÃO, J. O impacto social da AIDS no Brasil: relatório final. Rio de Janeiro, Associação Brasileira Interdisciplinar de AIDS, maio 1988.

Pesquisa piloto que traça um perfil socioeconômico dos casos notificados de AIDS no estado do Rio de Janeiro, de 1982 a 1988, a partir das 500 fichas arquivadas na Secretaria Estadual de Saúde. Constata que a maioria dos casos é de homens classificados como homossexuais (202) e bissexuais (101), entre 20 e 45 anos de idade, solteiros, de nível escolar médio-baixo, de várias categorias ocupacionais e profissionais e das camadas médias e médias-baixas da população. Este perfil, no entanto, não corresponde à imagem veiculada 
pelas campanhas oficiais de prevenção, ou mesmo ao estereótipo popular do gay bem-sucedido do mundo da moda e do meio artístico. Propõe que a história social da epidemia seja conhecida, para que as medidas de prevenção divulgadas sejam pertinentes e eficazes.

HECKER FILHO, Paulo. Um tema crucial. Porto Alegre: Sulina, 1989.

Na perspectiva da crítica literária, o autor analisa as possíveis relações entre homossexualidade e criação literária, a partir de obras de escritores ocidentais, modernos reconhecidamente homossexuais.

LACEY, E. A. "Latin America: myths and realities" [América Latina: mitos e realidades]. Gay Sunshine, n. 40/41. p. 22-31, 1979.

Panorama de diversos aspectos culturais, sociais e históricos da homossexualidade masculina na América do Sul. São levantados os diversos modos de comportamentos homossexuais nos países do continente, inclusive o Brasil. Os mitos que cercam as práticas homossexuais são vistos à luz da repressão e do preconceito.

LAURENTI, Ruy. "Homossexualismo e a Classificação Internacional de Doenças". Rev. de Saúde Pública, v. 8, n. 5, p. 344-345, out. 1984.

Este editorial, apresentado pelo diretor do Centro da OMS para a Classificação Internacional de Doenças, refere-se ao fato de que nos últimos anos os grupos homossexuais de países ocidentais têm solicitado às instituições de saúde a retirada do código 302.0 da Classificação Internacional de Doenças (CID). Este código inclui o "homossexualismo", no Capítulo VI, que trata de transtornos mentais. $\mathrm{O}$ autor esclarece que essa retirada não cabe aos orgãos que revisam a CID mas à psiquiatria que, por tradição, tem se ocupado do assunto. Alerta que um código para o homossexualismo continuará a existir na CID enquanto houver estatísticas ou consultas médicas sobre ele; o mesmo poderá ocorrer com a heterossexualidade, caso este comportamento venha a se tornar causa de desconforto ou discriminação, necessitando consulta clínica.

LIMA, Délcio Monteiro de. Os homoeróticos. Rio de Janeiro: Francisco Alves, 1983.

Pesquisa que visa mostrar ao leitor leigo a problemática do homossexualismo brasileiro. Segundo o autor, existem 13 milhões de homens e mulheres no Brasil engajados nessas práticas sexuais ditas não convencionais. Foi seu propósito refletir sobre a dimensão humana do homossexualismo no 
passado e no presente, através de sua história no Brasil e em outros países, e indicar o seu caminho futuro.

LOBERT, Rosemary. A palavra mágica Dzi: uma resposta difícil de perguntar. Campinas: Unicamp, 1979. Dissertação de Mestrado em Antropologia Social, incluindo ilustração fotográfica.

Ao acompanhar como observadora-participante a trajetória do grupo músico-teatral "Dzi Croquetes" pelos palcos brasileiros e estrangeiros, a pesquisadora pôde observar como o elenco construiu seu espetáculo, extremamente original e instigante, baseando-se na negação dos papéis de gênero e dos valores a estes associados. O clima de anarquia que reinava no palco e a androgenia dos atores permitiu entrever a produção de um novo espaço de relacionamento sexual e social, desafiador dos rótulos estabelecidos.

MACRAE, Edward. "Os respeitáveis militantes e as bichas loucas". In: Alexandre Eulálio etal., Caminhoscruzados; linguagem, antropologiae ciências naturais. São Paulo: Brasiliense, p. 99-111, 1982.

Relata um caso ocorrido em São Paulo, de 1980 a 1981, entre representantes de um jornal alternativo da Convergência Socialista e militantes do Movimento Homossexual, convidados para formar uma editoria homossexual naquela publicação. As divergências que surgiram quanto à linguagem e à forma de reivindicação a serem adotadas serviu para elucidar outras questões correlatas. A militância homossexual, desde os anos 20 na Europa até o Brasil à época do artigo, oscilava entre uma atuação "escandalosa", "caricata" e "fechativa", em que todos os valores são objeto de zombaria, e uma atuação "séria", "responsável" e "sem alardes", em que a crítica é explícita. Sugere o autor que a militância "fechativa" é dotada de maior poder de inquietação, pois leva a um questionamento mais profundo das normas e atitudes preconcebidas.

MACRAE, Edward. "Em defesa do gueto". Novos Estudos Cebrap, v. 2, n. 1, p. $53-60$, abr. 1983 .

Ao focalizar as áreas centrais da cidade de São Paulo, observa que o mercado homossexual vem se ampliando e despontando publicamente. Analisa essas mudanças locais à luz de sua inserção no contexto urbano brasileiro desde a década de 1960, destacando fatos e figuras da época que contribuíram para aumentar a aceitação para a homossexualidade no mercado de bens culturais e de consumo. 
MACRAE, Edward. "Homossexualidade e individualismo". Anais. São Paulo: Abep, v. 1, p. 563-574, 1984. IV Encontro da Associação Brasileira de Estudos Populacionais, águas de São Pedro.

Articulando o estudo de E. Zaretski (sobre o capitalismo, a família e o surgimento da identidade pessoal), e as idéias de L. Dumont sobre o individualismo como sistema de representações nas sociedades modernas, o autor discute as distintas formas de apropriação da categoria de individualismo pelos movimentos feminista e homossexual. Analisa alguns artigos de autores que rejeitamo "ser" homossexual em favor de um "estar" individual mais autônomo e sem classificação social. Do estudo de Masters and Johnson sobre homossexualismo, destaca a idéia de que o relacionamento homossexual, distinto do relacionamento heterossexual reprodutivo, retém a liberdade do gozo sem o envolvimento subjetivo. No final, afirma que o estilo de vida homossexual, voltado para o hedonismo e para o sexo descompromissado e de consumo, é uma tendência atual das classes médias urbanas brasileiras, a despeito das barreiras tradicionais.

MACRAE, Edward. "A homossexualidade”. In: Moacir Costa et al., Macho, masculino, homem. Porto Alegre: L\&PM, p. 64-71, 1986.

Apresenta o ponto de vista de cientistas sociais ingleses e americanos, em particular Mary McIntosh, em que a homossexualidade não é vista como uma condição, mas como um papel social e historicamente definido. Seguem-se breve estudo das mudanças ocorridas nas categorizações da homossexualidade no Brasil e comentários sobre a sua reclassificação como "Outras Circunstâncias Psicossociais" pelo Conselho Federal de Medicina, em 1985, ao invés de "Desvio e Transtorno Sexual", de código anterior. Sugere o autor que essa reclassificação poderá afetar o status médico da homossexualidade diante da AIDS no Brasil, posto que o iguala à heterossexualidade. O mal a combater passará a ser o vírus e não os homossexuais.

MACRAE, Edward. "AIDS - Prevenção ou novo tipo de segregacionismo?" Temas do Imesc, v. 4, n. 1, p. 73-81, 1987.

Questiona os discursos e as campanhas preventivas contra a AIDS e pergunta se eles não conteriam o esboço de uma nova forma de disciplina e repressão à sexualidade, sobretudo à homossexualidade masculina. Alerta para o fato de que o discurso médico preventivo e informativo sobre AIDS também poderá tornar mais agudo o preconceito e a repressão às práticas homossexuais. 
MACRAE, Edward. "Os homossexuais, a AIDS e a medicina". Radis Tema, Rio de Janeiro: Fiocruz, v. 5, n. esp., p. 41-47, out. 1987.

Através da análise de mudanças históricas e culturais ocorridas nos últimos 50 anos, procura compreender o lugar da homossexualidade na sociedade brasileira contemporânea e os efeitos da AIDS na experiência homossexual. Quanto à AIDS, são examinadas as mudanças que estariam ocorrendo em certas práticas homossexuais, com vistas a prevenir a transmissão do vírus. Questiona se as mudanças oficialmente recomendadas são de fato baseadas em critérios científicos confiáveis, ou se um moralismo disfarçado não estaria permeando a linguagem científica e a ciência médica.

MACRAE, Edward. A construção da igualdade: identidade sexual e política no Brasil da abertura. Campinas: Unicamp, 1990.

Estudo em profundidade sobre o movimento de liberação homossexual no Brasil da "abertura", no final dos anos 70 e início dos 80 . A partir de sua vivência pessoal nesse meio e de depoimentos de outros militantes, o autor articula uma dupla problemática: a dos movimentos sociais e a da homossexualidade. $O$ enfoque privilegia a construção social e cultural da sexualidade e nega sua suposta naturalidade. O surgimento do movimento homossexual e o lugar que ocupa, enquanto fenômeno político na sociedade brasileira nesse período, são vistos como parte da construção dessa identidade.

MENDES, R. Leite. "Les apparences en jeu". Sociétés, Paris, n. 17, p. 7-11, mars. 1988.

Trata da construção e afirmação de identidades e papéis homossexuais, especialmente na região Nordeste do Brasil. Mostra a dificuldade de se trabalhar com categorias estanques e aponta para a importância dos jogos de aparência e da ambigüidade sexual para se compreender o comportamento homossexual brasileiro.

MISSE, Michel. O estigma do passivo sexual. Rio de Janeiro: Achiamé, 1979.

Ao discutir a forma ideológica de estigmatização que se manifesta para além das relações interpessoais objetivas, o autor marca uma posição contrária às teses de E. Goffman. Para reforçar seu argumento, analisa um setor do discurso cotidiano e desencava o termo passivo sexual como o símbolo de estigma próprio à ideologia da feminilidade; mostra como este termo se estende, por deslocamentos imperceptíveis, para caracterizar determinadas práticas homossexuais masculinas como passivas, assemelhando-as à função sexual da mulher como "receptora" do pênis. O status de normalidade se restringe ao 
homem "ativo", "insertor", mesmo que a relação sexual seja homossexual. No caso do homossexual "passivo", objeto de inúmeras referências pejorativas, os termos indicam uma dupla acusação: de ter se tornado "feminino" e de ter traído a sua condição "natural" de macho ativo e dominante, tanto nas relações sexuais quanto sociais.

MORAES, Joanides Hiroito. Boca do lixo. São Paulo: Populares, 1977.

Descreve de forma etnográfica e cartográfica uma grande área no centro de São Paulo, onde se concentram prostitutas, travestis, homossexuais e prostitutos. Além de tratar de aspectos referentes à sua história e às mudanças urbanas ocorridas, também considera o cotidiano das populações que ali convivem.

MOTT, Luiz. Dez viados em questão: tipologia dos homossexuais na cidade de Salvador, Bahia. Comunicação apresentada na XIII Reunião da Associação Brasileira de Antropologia, São Paulo, 4-7 abr. 1982.

Pesquisa exploratória que visa delinear e descrever o estilo de vida de dez "tipos" de homossexuais masculinos da cidade de Salvador, a partir de três grandes grupos: travestis, bichas e bofes. Paralelamente, refere-se aos diferentes modos de "ser homossexual" na sociedade brasileira no começo dos anos 80.

MOTT, Luiz. A homossexualidade: uma variável esquecida pela demografia histórica. Comunicação apresentada no III Encontro da Associação Brasileira de Estudos Populacionais, Vitória, out. 1982.

Chama a atenção dos demógrafos historiadores brasileiros para a importância de incluir a homossexualidade e os homossexuais como área legítima de estudo populacional; mostra como a homossexualidade e a homofobia são correlacionadas e mais bem entendidas se vistas à luz de variáveis demográficas; e, finalmente, ilustra com o estudo de um caso específico — os sodomitas no Brasil colonial - as bases que sustentam sua argumentação.

MOTT, Luiz. "AIDS: reflexões sobre a sodomia”. Comunicações do Iser, Rio de Janeiro, v. 4, n. 17, p. 32-41, dez. 1985.

Discute os preconceitos que associam homossexualidade e AIDS, principalmente aqueles fundamentados e disseminados por diversas religiões e cultos. Exemplifica com o culto de Testemunhas de Jeová, em que os homossexuais são culpabilizados pela origem da epidemia no Ocidente. Baseando-se em fatos históricos e testemunhos, o artigo busca desmistificar tal associação, além dc 
discutir o tratamento dado à sodomia pela Igreja Católica e a Santa Inquisição no Brasil.

MOTT, Luiz. "A homossexualidade no Brasil: bibliografia". In: Dan C. Hazen (ed.), Latin American masses and minorities: their images and realities. New Jersey: Princeton University, v. 2, p. 592-609, 1985.

Reune uma bibliografia eclética, com mais de 260 títulos, sobre homossexualismo masculino e feminino no Brasil e temas correlatos. Apresenta-se como o primeiro no gênero no país, com intuito de atrair novos pesquisadores e de servir como fonte de referência para aqueles que se interessam por essa questão.

MOTT, Luiz. "Escravidão e homossexualidade". In: Ronaldo Vainfas et al., História da sexualidade no Brasil. Rio de Janeiro: Graal, p. 19-40, 1986. Trata da homossexualidade masculina no Brasil colonial e imperial. O relato, rico em detalhes etnográficos, destaca as relações inter-raciais, homossexuais e os aspectos da cultura negra e branca, bem como os modos de relacionamento sexual na época.

MOTT, Luiz. A vênus de sodoma: a penetração do preservativo no Brasil pós-AIDS. Comunicação apresentada no Congresso Brasileiro de Neurologia e Higiene Mental, Fortaleza, 1987.

Estudo antropológico sobre a utilização dos preservativos nas campanhas contra a AIDS no Brasil. São abordados aspectos históricos e culturais, como a origem dos preservativos no Brasil, os preconceitos envolvidos e o lugar que os preservativos vêm ocupar na luta contra a AIDS. Os preconceitos que associam a AIDS à homossexualidade também são discutidos.

MOTT, Luiz. Escravidão, homossexualidade e demonologia. São Paulo: ícone, 1988.

Aprofunda suas análises e levantamentos etnográficos anteriores sobre a homossexualidade no Brasil colonial e imperial, enfocando as relações interraciais e os aspectos culturais, históricos e religiosos. As estruturas de poder e de dominação são destacadas, em sua relação com a sexualidade, para se compreender a homossexualidade no Brasil.

MOTT, Luiz. "Cupido na sala de aula: pedofilia e pederastia no Brasil antigo". Cadernos de Pesquisa, São Paulo, n. 69, p. 32-39, maio 1989. 
Com base em documentos inquisitoriais, o autor acompanha a evolução da ideologia luso-brasileira no tocante às relações sexuais intergeracionais, privilegiando a análise de uma denúncia contra um professor supostamente pedófilo em Minas Gerais nos meados do século XVIII.

MOTT, Luiz. "Os médicos e a AIDS no Brasil". Ciência e Cultura. São Paulo, p. 5-12, 1989.

Focaliza os depoimentos de médicos de diversas cidades do Brasil sobre a AIDS, para mostrar suas contradições, erros e preconceitos. Apesar disso, essas opiniões vêm sendo reproduzidas e divulgadas pelos meios de comunicação, gerando notícias distorcidas e equivocadas com amplo alcance. Além de fomentar a "AIDSteria", o novo surto de "homofobia" indica um recrudescimento dos preconceitos e da intolerância que envolve a homossexualidade e os homossexuais. Conclui que a luta contra a AIDS tem se deslocado para a luta contra a homossexualidade.

OKITA, Hiro. Homossexualismo: da opressão à libertação. São Paulo: Proposta, 1980.

Pequeno ensaio sobre as raízes da opressão à homossexualidade masculina no Ocidente capitalista cristão, numa perspectiva marxista. Amplamente divulgado na época de seu lançamento, foi lido como uma "cartilha" pelos miliantes do movimento homossexual brasileiro no início dos anos 80 .

PARKER, Richard G. "Masculinity, femininity, and homosexuality: on the anthropological interpretation of sexual meanings in Brazil". [Masculinidade, feminilidade e homossexualidade: sobre a interpretação antropológica dos significados sexuais no Brasil] In: Evelyn Blackwood (ed.), Anthropology and homossexual behavior. New York: Haworth, p. 155163, 1986.

Ensaio que examina a interpretação antropológica dos significados sexuais no Brasil, a partir dos trabalhos de Peter Fry e outros. Ao focalizar a ideologia sexual e homossexual, sugere que estas dimensões da cultura somente adquirem pleno sentido se forem inseridas no contexto mais amplo dos significados sexuais no Brasil. É delineada a trajetória histórica dos sistemas de classificação sexual que tem estruturado as identidades sexuais na realidade brasileira.

PARKER, Richard G. "Acquired Immunodeficiency in Urban Brazil”. Medical Anthronologv Ouarterly, new caries 1(2): 155 175, 1987. 
Original em inglês do artigo "A AIDS no Brasil urbano", citado abaixo.

PARKER, Richard G. "Sexual culture and AIDS education in urban Brazil" [Cultura sexual e educação sobre AIDS no Brasil urbano]. In: R. Kulstad (ed.), AIDS 1988: AAAS Symposia Papers. Washington: American Association for the Advancement of Science, p. 169-173, 1988.

Discute a AIDS no contexto urbano brasileiro e examina o conhecimento que se tem da epidemia à luz da cultura sexual. Argumenta que o Brasil, apesar de enquadrado no Padrão I de transmissão do HIV, juntamente com os Estados Unidos e países da Europa Ocidental, revela importantes diferenças quanto às práticas homossexuais e bissexuais, bem como aos significados atribuídos a essas práticas. Enfatiza que o processo de construção social e cultural da vida sexual no Brasil terá de ser conhecido e compreendido para que os programas de educação sobre AIDS sejam pertinentes para esta realidade.

PARKER, Richard G. "Youth, identity and homosexuality: the changing shape of sexual life in contemporary Brazil" [Juventude, identidade e homossexualidade: as mudanças na vida sexual no Brasil contemporâneo]. Journal of Homosexuality, v. 17, b. 3/4, p. 269-289, 1989.

Examina a relação entre homossexualidade e adolescência no Brasil contemporâneo, focalizando a distinção entre dois diferentes sistemas de significados que estruturam as relações sexuais entre parceiros do mesmo sexo: o modelo tradicional, dominante nas áreas rurais, e o conjunto de noções mais modernas, de importância crescente nos centros urbanos. Analisa como estes sistemas vêm afetando a experiência do desejo e as práticas sexuais de indivíduos adolescentes e jovens. Sugere, ao final, que a emergência de uma nova subcultura sexual nos grandes centros urbanos brasileiros ampliou significativamente o escopo de escolhas sexuais disponíveis para a juventude masculina e feminina, abrindo novas possibilidades, mais fluidas e diversificadas, de relacionamento.

PARKER, Richard G. "A AIDS no Brasil urbano". Cadernos do IMS, Rio de Janeiro: UERJ, Instituto de Medicina Social, vg. 3, n. 1, p. 111-147, 1989. Visa a contribuir para uma compreensão transcultural da AIDS, através do estudo da epidemia no Brasil. Desde 1982, quando o primeiro caso foi diagnosticado, o rápido aumento do número de pessoas com AIDS logo colocou o Brasil entre os primeiros países com casos confirmados em todo o mundo. Apesar disso, a epidemia vem recebendo pouca atenção, tanto da comunidade internacional quanto do próprio governo brasileiro; o modelo cpidemiológico 
de transmissão do HIV provém de países socioculturamente distintos, e nem sempre reflete a realidade do país. Dados de pesquisas anteriores do autor sobre a cultura sexual brasileira no meio urbano the permitem compreender melhor os padrões locais de transmissão do HIV e a AIDS. Reivindica medidas culturalmente adequadas para desenvolver as políticas de prevenção e um exame profundo do modo pelo qual as doenças revelam, a um só tempo, processos biológicos e socioculturais.

PARKER, Richard G. "Bodies and pleasures: on the construction of erotic meanings in contemporary Brazil" [Corpos e prazeres: sobre a construção de significados eróticos no Brasil contemporâneo]. Anthropology and Humanism Quarterly, v. 14, n. 2, p. 58-64, 1989.

Se o estudo de gênero tornou-se objeto da investigação antropológica, o estudo de sexo tem recebido pouca atenção. A dimensão erótica, o mais das vezes atrelada ao sexo, se enquadra no mesmo modelo explicativo da sexualidade, ou seja, são as estruturas do poder que lhe emprestam sentido. A partir de pesquisas realizadas no Brasil, o autor propõe uma perspectiva alternativa para examinar o erotismo como um sistema de significados social e culturalmente construídos. E mais, como um sistema relativamente autônomo. Sugere que a experiência erótica, como outras experiências humanas, é constituída de teias de significado calcadas nas práticas sexuais da vida coletiva. Palavras, imagens, mitos, rituais, fantasias e desejos adquirem forma e substância neste fluxo, sem a mediação das ideologias tradicionais de gênero e classe social ou de categorias científicas formais. Apesar de não se referir explicitamente à homossexualidade masculina, essa visão é útil para compreender a dimensão erótica dessa prática no Brasil.

PARKER, Richard G. "Responding to AIDS in Brazil" [Respondendo à AIDS no Brasil]. In: D. Moss e B. Mistzal (eds.), Action on AIDS: national policies in comparative perspective. Westport: Greenwood, p. 51-71, 1990.

Discute as estatísticas da AIDS no Brasil e a resposta da sociedade civil e do programa governamental à epidemia. Constata que o quadro de estereótipos que retrata a face da AIDS brasileira não reflete o percurso da epidemia na população e ignora a especificidade dos contextos sociais e culturais em que as atitudes e práticas sexuais se estruturam. As políticas oficiais de saúde, mal definidas e atrasadas em relação à epidemia, têm suscitado uma gama de respostas em nível local. Novos grupos voluntários de apoio e de prevenção vêm se formando desde 1985, atuando diretamente junto 
à população e questionando a omissão e a desinformação do governo. $\mathrm{O}$ contexto e a história social da AIDS tendem a reproduzir a própria história brasileira, fato que terá de ser considerado ao se formularem respostas para a epidemia no futuro.

PARKER, Richard G. Male prostitution, bisexual behavior, and HIV transmission in urban Brazil [Prostituição masculina, comportamento bissexual e transmissão do HIV no Brasil urbano]. In: T. Dyson (ed.). Sexual behavior and networking: socio-cultural studies on the transmission of HIV. Liege: Ondina Editions, 1991.

Utiliza dados de uma pesquisa etnográfica realizada no Rio de Janeiro para examinar o relacionamento entre, de um lado, as diversas formas de prostituição masculina e de comportamento homossexual e bissexual e, de outro, a transmissão do HIV no Brasil urbano. São focalizadas a construção social das interações sexuais entre pessoas do mesmo sexo e as diferenças significativas que estruturam a prostituição masculina e a dos travestis. Finalmente, ao situar a relação prostituto/cliente em um contexto mais amplo, analisa as implicações que estes diversos padrões de comportamento sexual encerram para a transmissão do HIV e para a prevenção da AIDS na população brasileira.

PARKER, Richard G. Corpos, prazeres e paixões: A cultura no Brasil contemporâneo. São Paulo: Best Seller, 1991.

Estudo etnográfico e histórico que analisa a cultura sexual no Brasil. O autor propõe que existem diversas perspectivas sobre a sexualidade na cultura brasileira, e que essas perspectivas têm um papel fundamental na construção da diversidade sexual. Analisa os sistemas de gênero, sexualidade e erotismo, dando ênfase especial à questão da homossexualidade, vista de diversos ângulos.

PARKER, Richard G., GUIMARÃES, C.D., e STRUCHINER, C.J.The impact of AIDS health promotion for gay and bissexual men in Rio de Janeiro, Brazil [O impacto de medidas de promoção da saúde para AIDS em homens homossexuais e bissexuais do Rio de Janeiro, Brasil]. UERJ, Instituto de Medicina Social. Preparado para o WHO/GPA Workshop on AIDS Health Promotion Activities Directed Towards Gay and Bisexual Men, 29-31 maio 1989.

Partindo de dados de uma pesquisa piloto, foi examinado o impacto das estratégias de prevenção contra AIDS no universo homossexual e bissexual masculino no Rio de Janeiro. Os dados médicos disponíveis sobre os padrões 
de soroprevalência do HIV, ainda que limitados, permitiram uma primeira análise da construção social e cultural das relações sexuais entre homens. Além disto, os materiais informativos dirigidos ao homossexual e ao bissexual masculino foram examinados, bem como as estratégias e pressupostos que orientam a produção e disseminação desses materiais. As mudanças de atitude e de comportamento que estariam ocorrendo nessa população indicam uma gama de modalidades sexuais possíveis de serem adotadas para reduzir o risco de transmissão do HIV no futuro.

PEREIRA, Carlos A. Messeder. "Desvio e/ou reprodução: o estudo de um caso". In: Everardo P. G. Rocha et al., Testemunha ocular: textos de antropologia social do cotidiano. Rio de Janeiro: Tempo Literário, p. 102-127, 1979.

Aborda aspectos culturais e sociais envolvidos nas relações estáveis, ou "conjugais", entre homossexuais masculinos, utilizando como objeto de análise um caso "conjugal" particular. Após um exame cuidadoso da linguagem, visto como organizadora lógica da experiência social dos atores e como expressão de esquemas mais profundos, percebe-se a coerência entre as categorias utilizadas e o próprio modelo da relação. $\mathrm{O}$ autor propõe que o comportamento sexual tido como desviante, segundo as regras e valores sancionados socialmente, poderá reproduzir noutro nível menos explícito todo um conjunto de padrões inscritos na ordem social.

PEREIRA, Ricardo C. O desperdício do sêmen: um estudo do erotismo entre rapazes. Salvador: Universidade Federal da Bahia, 1988. Dissertação de Mestrado em Ciências Sociais.

Nesse estudo o autor busca compreender os preconceitos e a repressão à homossexualidade masculina no Ocidente, através do exame crítico de aspectos históricos e culturais e das relações homossexuais no Brasil desde os tempos coloniais até a chegada da AIDS.

PERLONGHER, Néstor Osvaldo. "El mundo gay en Brasil: visión del paraíso". Cerdos \& Pesces. Buenos Aires, n. 4, jul. 1984.

O autor, natural da Argentina, relata suas impressões de viagem nas cidades do Rio de Janeiro e São Paulo, e em particular o mundo das transações homossexuais masculinas. 
PERLONGHER, Néstor Osvaldo. "O contrato da prostituição viril". Arquivos Brasileiros de Psicologia. Rio de Janeiro, v. 37, n. 2, p. 94-105, abr./jun. 1985.

Descreve e analisa um tipo particular de contrato que regula a prestação de serviços entre prostitutos jovens e hipermasculinos e os clientes homossexuais, em troca de uma retribuição econômica. A partir da observação direta de uma área central da cidade de São Paulo, os atributos valorizados pelos atores e espectadores da transação foram agrupados em séries de idade, de classe e de gênero, com o objetivo de dimensionar os mecanismos de atribuição de valor ao corpo prostituído. É freqüente a transgressão do contrato estabelecido, ocasionando a violência. Propõe como hipotese que esta violência é inerente à promessa de masculinidade colocada à venda no contrato da prostituição viril.

PERLONGHER, Néstor Osvaldo. "Amor e comércio na prostituição viril". Anais. São Paulo: Abep, v. 1, p. 587-606, 1984. IV Encontro da Associação Brasileira de Estudos Populacionais, águas de São Pedro.

Discute as relações circunstanciais da prostituição viril, levando em conta as oposições de idade, classe e gênero presentes na relação michê/cliente. A ligação afetiva entre sujeitos socialmente desiguais é analisada, constituindo uma rara abordagem do discurso sentimental na prostituição viril. As representações e os significados que a noção de homossexualidade assumem nesta relação são também dissecadas em profundidade.

PERLONGHER, Néstor Osvaldo. "O ghetto e a boca: a territorialidade homossexual. Espaços e Debates, São Paulo, v. 6, n. 17, p. 54-66, 1986.

Traça algumas considerações sobre a "geografia homossexual", analisando os modos de ocupação urbana de populações envolvidas em práticas homossexuais masculinas, sobretudo no centro de São Paulo. É questionado o uso das noções de "região moral", "ghetto" e "boca" para estudar o caso de São Paulo; cita os Estados Unidos para mostrar como são específicas a identidade e a subjetividade homossexual nos grandes centros urbanos. Os modos de "ser" homossexual são perpassados por diferenças culturais e pela história de repressão que marcam estes espaços.

PERLONGHER, Néstor Osvaldo. "A tipologia das homossexualidades numa pesquisa social”. Anais. São Paulo: Abep, v. 1, p. 193-212, 1986. V Encontro da Associação Brasileira de Estudos Populacionais. (Também publicado em Cadernos do IMS, Rio de Janeiro: UERJ, Instituto de Medicina Social, v. 2, n. 3, p. 73-96, ago./set. 1988). 
Artigo crítico do livro de Bell e Weinberg, Homossexualities, no que se refere à homossexualidade masculina. Segundo Perlongher, a abordagem da sexologia behaviorista americana, adotada no livro, ao mesmo tempo descritiva e prescritiva, ignora a força dos condicionantes que as normas do meio homossexual impõem. A cumplicidade que liga a nova ordem sexual à antiga é subestimada; abre-se um novo círculo vicioso de adaptação às normas impostas pelo meio, tão repressoras quanto a ordem antiga que se pensava deixar para trás.

PERLONGHER; Néstor Osvaldo. "Vicissitudes do michê". Temas Imesc, v. 4, n. 1, p. 57-71, 1987.

Artigo sobre a prostituição viril, no qual se aborda o funcionamento desejante desse modo de transação homossexual masculina. Examinam-se em detalhe temas como o desejo, a estética, o lugar do dinheiro, os movimentos e as histórias de clientes e prostitutos.

PERLONGHER, Néstor Osvaldo. O que é AIDS? São Paulo: Brasiliense, 1987. Coleção Primeiros Passos.

Pequeno livro para divulgação ampla, com informações básicas sobre a AIDS, a fábula de suas origens, a epidemia no Brasil, a homossexualidade e o poder médico. Finaliza com algumas reflexões acerca da vida, da morte e do desejo.

PERLONGHER, Néstor Osvaldo. "Territórios marginais". Cadernos Avulsos,

Rio de Janeiro: UFRJ, Centro de Estudos Contemporâneos, n. 6, 1988.

Artigo que estuda a conformação das territorialidades ditas marginais no espaço urbano, à luz das idéias de autores como G. Deleuze e F. Guattari. Relaciona os aspectos desejantes, intersubjetivos e geográficos envolvidos na conformação e no funcionamento dos territórios, assim como suas práticas e seus rituais. Através da noção "código-território", analisa-se a configuração das populações marginais e são vislumbrados os modos distintos de produção da subjetividade.

PERLONGHER, Néstor Osvaldo. O negócio do michê: a prostituição viril. São

Paulo: Brasiliense, 1988.

Pesquisa etnográfica em profundidade que, partindo das representações gerais do universo do michê, atinge a ação "molecular" da vida cotidiana. A primeira parte do livro apresenta uma "cartografia" dos personagens sociais envolvidos no jogo de relações homossexuais na cidade de São Paulo e a sua 
distribuição espacial nas áreas do centro; a segunda parte dá vida à "cartografia", descrevendo e analisando os circuitos da relação michê/cliente, assim como os critérios simbólicos e materiais que definem a troca comercial. O tema central de todo o estudo é o desejo nas suas múltiplas formas malditas.

PETRI, Valéria. Sexo, fábulas e perigos. São Paulo: Iglu, 1988.

Focaliza as doenças sexualmente transmissíveis, em particular a AIDS, através de relatos e reflexões gerados na experiência clínica da autora, que é médica. São criticadas as associações preconceituosas estabelecidas, por médicos e leigos, entre a AIDS e a homossexualidade.

SELL, Teresa Adada. Identidade homossexual e normas sociais. Florianópolis: Universidade Federal de Santa Catarina, 1987.

Estudo de psicologia social que, através de entrevistas com indivíduos homossexuais masculinos, reconstitui suas histórias de vida. Tenta compreender como é formada a identidade sexual desses indivíduos, levando em conta fatores tais como os preconceitos, a origem geográfica e a classe social.

SILVA, José Fábio Barbosa da. "Aspectos sociologicos do homossexualismo em São Paulo”. Sociologia, São Paulo: USP, v. 21, n. 4, p. 350-360, 1959. Artigo pioneiro sobre grupos homossexuais na cidade de São Paulo, do ponto de vista sociologico. Trabalha com a escala Kinsey para estimar o número de homossexuais masculinos exclusivos e com a idéia de "região moral", de Park, para delimitar as áreas de maior concentração homossexual no centro da cidade. Além de analisar os tipos de comportamento homossexual preodominantes (passivo, duplo e ativo), discute os motivos que levam à interação e à formação de grupos homossexuais, assim como os códigos simbólicos que thes garantem reconhecimento e visibilidade pública. Por fim, constata que, apesar do comportamento sexual ser a base inicial da interação, os critérios de estruturação dos grupos seguem os mesmos critérios de lazer da sociedade em geral.

SILVA, Lindinalva Laurindo da. AIDS e homossexualidade em São Paulo. São Paulo: PUC, 1986. Dissertação de Mestrado em Antropologia.

Trata de questões relacionadas a AIDS e homossexualidade, a partir de uma pesquisa realizada em São Paulo junto a pessoas HIV-positivos e com AIDS, bem como homossexuais em geral. São descritas as práticas e o estilo de vida homossexual, juntamente com as representações que foram criadas em torno da doença - principalmente as do doente diante da AIDS. A percepção 
que os médicos detêm da doença e do doente é vista como parte da construção da AIDS na ordem social. Finalmente, é relatada a maneira pela qual certos setores da população homossexual reagem à epidemia e quais os modos de mobilização empregados diante das atitudes discriminatórias.

SOUZA, Carlos Alberto Crespo de. "A homossexualidade ao longo dos tempos — uma contribuição ao seu estudo". Jornal Bras. de Psiquiatria. Rio de Janeiro: UFRJ, v. 38, n. 6, p. 321-326, nov./dez. 1989.

Ensaio que realiza um percurso através das imagens bíblicas até a modernidade, para apresentar as concepções e os comportamentos que a "cultura" tem adotado face à homossexualidade. Com esse traçado de idéias e de autores, pretende promover a reflexão da psicoterapia sobre a homossexualidade. A experiência psicoterapêutica do autor com "pessoas que sofrem por possuírem desejos ou sentimentos inaceitáveis" o leva a concluir que a homossexualidade é uma expressão da disfunção afetivo-sexual. Propõe que seja este o foco do trabalho terapêutico.

TEIXEIRA, Maria Lina Leão. Transas de um povo de santo: um estudo sobre as identidades sexuais. Rio de Janeiro: UFRJ, Instituto de Filosofia e Ciências Sociais, 1986. Dissertação de Mestrado em Sociologia.

Aborda a construção de identidades sexuais em relação aos aspectos culturais e seus determinantes, utilizando como campo de estudo as comunidades religiosas do candomblé. Segundo a autora, essas comunidades detêm modos singulares de identificação sexual, e são as práticas homossexuais valorizadas de modo distinto das outras crenças religiosas.

TEIXEIRA, Maria Lina Leão. "Lorogun: identidades sexuais e poder no candomble”. In: MOURA, Marcondes de (org). Candomblé, desvendando identidades. São Paulo: E.M.W., p. 33-52, 1987.

Estudo antropológico sobre as estruturas de poder no candomblé, procurando compreender o lugar e a função da homossexualidade na organização hierárquica das comunidades religiosas.

TERTO Jr., Veriano. No escurinho do cinema: sociabilidade orgiástica nas tardes cariocas. Rio de Janeiro: PUC, 1989. Dissertação de Mestrado em Psicologia.

Estudo interdisciplinar - psicológico e antropológico - sobre as chamadas perversões sexuais masculinas a partir de pesquisa de campo realizada em uma sala de cinema no centro do Rio de Janeiro. A etnografia descreve a 
arquitetura do local, as múltiplas práticas homossexuais, a pornografia, o travestismo, a orgia e o cotidiano da sala, inclusive os filmes ali apresentados. A análise focaliza a conformação do erotismo e da homossociabilidade próprias àquele cinema, bem como os modos singulares de viver a sexualidade como orgia.

TREVISAN, João Silvério et al. “As minorias sexuais”. In: G. Mantega (org.), Sexo e poder. 1. ed. São Paulo: Brasiliense, p. 129-136, 1979.

Registro de uma mesa-redonda em torno do tema "minorias", com a participação de representantes de grupos homossexuais, associações feministas e do movimento negro. Trevisan, membro do grupo Somos de São Paulo e um dos fundadores do jornal Lampião, questiona o comportamento patriarcal da sociedade capitalista e sugere que o conceito de ação política seja ampliado para englobar as "minorias" em geral.

TREVISAN, João Silvério. Devassos no paraíso. São Paulo: Max Limonad, 1986. Orig. inglês - Perverts in Paradise. London: GMP Publishers, 1986.

Em estilo jornalístico é contada a história da homossexualidade no Brasil, desde os tempos coloniais até o início dos anos 80, com o advento da AIDS. São utilizados documentos históricos, textos literários, arquivos, jornais e periódicos, além da própria vivência e dos relacionamentos sociais do autor, para abordar os diversos aspectos religiosos, jurídicos, clínicos, sociais e políticos tratados no livro.

WERNER, Dennis. Laços sociais e bem-estar entre prostitutas femininas e travestis em Florianópolis. Comunicação apresentada no XVI Encontro da Associação Brasileira de Antropologia, São Paulo, mar. 1988.

Pesquisa antropológica que focaliza o lugar social da prostituição, seus modos de inserção e sua sociabilidade, principalmente entre travestis e prostitutas femininas. Analisa as entrevistas realizadas, em que prostitutas femininas falam da homossexualidade e do travestismo.

WHITAM, Frederick L. "The entendidos: middle class gay life in São Paulo" [Os entendidos: vida da classe média gay em São Paulo]. Gay Sunshine, n. $38 / 39$, p. $16-17,1979$.

Pequeno artigo que aborda o estilo de vida e as experiências de homossexuais masculinos de classe média de São Paulo, conhecidos como entendidos. $O$ autor opina que, sendo essa a mais rica cidade industrial do Brasil, a situação 
de classe desempenha importante papel na organização do segmento homossexual da população.

YOUNG, Allen. "Gay gringo in Brazil" [Gringo gay no Brasil]. In: The Gay Liberation Book. San Francisco: Ramparts, p. 60-67, 1972.

Artigo de jornalista americano com suas impressões sobre o homossexualismo no Brasil no início da década de 70. Refere-se a uma acentuada divisão de papéis sexuais e à nítida hierarquia entre o "passivo" e o "ativo" na relação sexual entre parceiros masculinos. A partir de suas vivências, conclui que, no Brasil, ao contrário da militância gay americana, não se tolera uma homossexualidade vivida livre e ahertamente. Considera que este é um fator problemático para um eventual movimento homossexual.

\section{PERIÓDICOS}

BOLETIM DA ABIA. Rio de Janeiro: Associação Brasileira Interdisciplinar de AIDS, n. 1 - 11, 1988 - 90. Bimestral.

Publicação de distribuição gratuita, que oferece ao leitor um panorama atualizado e crítico sobre a AIDS no Brasil. A homossexualidade e a AIDS são matérias permanentes em todos os números, com o propósito de desmascarar os preconceitos e a discriminação gerados por este vínculo. A ABIA, uma das organizações não governamentais de maior repercussão no Brasil, tem usado o Boletim para estimular a comunidade a atuar de forma mais consciente e solidária contra a "terceira epidemia" do preconceito, principalmente no que tange aos direitos de cidadania das pessoas HIV-positivas ou vivendo com AIDS.

BOLETIM DO GGB. Salvador: Grupo Gay da Bahia, Fev. 1980. Quadrimestral (mimeo).

Publicação distribuída via assinatura sobre as atividades do GGB e questões pertinentes ao universo homossexual. Desde sua fundação, em fevereiro de 1980, o Boletim caracteriza-se por sua visão crítica e militante face às discriminações e violências praticadas contra homossexuais ("Homossexuais assassinados" é coluna permanente em todos os números) e pela divulgação de temas da atualidade ("No tabuleiro da baiana: sexo sem risco em tempo de AIDS", mar. 1990), além de outros informes de interesse local.

I.AMPIÃO D.4 ESQUINA. Rio de Jantiı. Esquina, abr. 1978-1981. Mensal. 
Jornal homossexual alternativo, criado por um conselho de jornalistas, escritores e outros profissionais e lançado para venda em bancas de jornal ou através de assinatura nos principais centros urbanos brasileiros. Embora não seja a única publicação dirigida para o público homossexual, foi a que manteve periodicidade regular e distribuição de maior alcance, com tiragens mensais de 12.000 a 15.000 exemplares. Marcando nítida diferença com as demais publicações homossexuais da época ou anteriores, o Lampião tratou de forma séria, mas não sem humor, a homossexualidade em toda a sua dimensão política e sociocultural. Até certo momento, também contribuiu para manter viva a militância homossexual. Sobre esta e outras publicações correlatas, ver P. Fry. "História da imprensa baiana". In: Lampião, ano 1, n. 4, 25 jul.-25 ago. 1978. p. 4; L. Míccolis. "Snob", 'La Femme'... os bons tempos da imprensa gay". In: Lampião, ano 3, n. 28, set 1980. p. 6-7; H. Daniel e L. Míccolis, Jacarés e lobishomens. Rio de Janeiro: Achiamé, 1983. p. 96-114; E. MacRae. A construção da igualdade: identidade sexual e política no Brasil da "abertura". Campinas, Unicamp, p. 65-93, 1990.

\section{RESUMO}

\section{Homossexualidade, Bissexualidade e HIV/AIDS no Brasil}

Uma Bibliografia Anotada das Ciências Sociais e Afins

Esta bibliografia anotada focaliza a produção das Ciências Sociais e áreas afins relativa à homossexualidade, bissexualidade e HIV/AIDS no Brasil. Engloba mais de cem publicações e documentos, e busca examinar as maneiras pelas quais essa literatura poderá contribuir para a compreensão e respostas mais efetiva à epidemia da AIDS na sociedade brasileira.

\section{SUMMARY}

\section{Homosexuality, Bisexuality, and HIV/AIDS in Brazil: An Annotated Bibliography of Social Science Publications}

This annotated bibliography focuses on the scientific and social scientific literature related to homosexuality, bisexuality and AIDS in Brazil. It covers more than one hundred publications and documents, and seeks to examine the ways in which this literature can contribute to a more effective understanding of and responso to the AIDS cpidcmic in Brazilian suclety. 


\section{RESUME}

\section{L'Homosexualité, la Bissexualité et le SIDA/HIV au Brésil: Une Bibliographie Commentée des Sciences Sociales et Connexes.}

Cette bibliographie commentée focalise la production des sciences sociales et domaines connexes au sujet de l'homosexualité, de la bissexualité et du SIDA/HIV au Brésil. Elle inclut plus de cent publications et documents et s'efforce d'analyser les façons dont cette littérature peut aider la société brésilienne à comprendre et à donner des réponses plus effectives à l'épidémie de SIDA. 
